\title{
Motivation and Obstacles to Adult Participation in Lifelong Learning Programs: The Effect of Gender and Age
}

\author{
Loukas Moustakas \\ University of the Aegean, Faculty of Humanities \\ Department of Preschool Education and Educational Design
}

Received 12 July 2018 • Revised 23 August 2018 - Accepted 30 August 2018

\begin{abstract}
The main purpose of this research paper is to identify all those parameters that are factors of motivation and obstruction in the participation of the inhabitants of the island of Rhodes in lifelong learning programs. Issues pertaining to adult education are addressed through the statements of the respondents to enhance this objective, while there is an attempt to identify differentiated parameters among people of different gender and age. Following the analysis of the respondents' statements, it was found that learning is to a great extent considered by the inhabitants of the island to be a stepping stone to overcome all sorts of difficulties they may encounter. Regarding the differences in age and gender statements, it is found that the most significant differences relating to the reasons for motivation are attributed to social and environmental grounds whereas in terms of the obstruction reasons statistically significant differences are found regarding the financial and work-related ones. These conclusions differ significantly with respect to the demographic characteristics of the sample, which in itself highlights the complexity of this issue and calls for further study and research.
\end{abstract}

Keywords: motivation reasons, obstacles, adult participation, lifelong learning programs, gender, age.

1. Introduction: Theoretical background

\subsection{Lifelong learning}

Lifelong learning includes any form of learning activity that takes place over a person's life and aims at acquiring or improving knowledge and skills. It contributes to the formation of an integrated personality, to social cohesion, to economic and cultural development, to professional integration and progress, as well as to the active participation of citizens in social and environmental issues (Oduaran, 2006; Pagge, 2005; Edwards, 2003; Bergevin, 1995; Nadler \& Nadler, 1995).

Benjamin Bloom argued that "at any age people actually learn to respond to a deep and powerful interest" (Koroneos, 2002). Learning is a process of personal change that is taking place for anyone to adapt to ever changing conditions and experiences, so it is clear that the context of lifelong learning refers to a system consisting of people going through transformation, who are called into action in a constantly changing world (Rogers, 2002; Bigge, 1990; Kolb, 1984). Although it occurs atypically from the early years of a person's life, it is founded on pre-school (C) Authors. Terms and conditions of Creative Commons Attribution 4.0 International (CC BY 4.0) apply. Correspondence: Loukas Moustakas, Faculty of Humanities, Department of Preschool Education \& Educational Design, University of the Aegean, 42, Pergialenis Street, Kremasti 85104 Rhodes, GREECE. Email: lmoustakas@aegean.gr. 
education and continues after the completion of formal or initial education throughout their adult life. It is a continuous process that accompanies a person continuously, either within the framework of the organized educational system or through numerous and varied learning experiences, taking place at informal or organized educational processes.

- Motivational reasons for participation mainly include personal pleasure, work, social background and financial state.

- Educational, organizational, labor and economic reasons are included as main obstacles to adults' lifelong learning.

- Economic and labor reasons are more significant for motivating women. On the contrary, high cost and family engagements are main obstacle reasons for them.

- The younger the participants, the greater the influence by their peers a fact inversely proportional to age.

The characteristics of lifelong learning, as described by the UNESCO Educational Institution (U.I.E.), forge the educational context within which a person advances throughout their life. According to the U.I.E. lifelong learning is characterized by (Goad, 1984):

- the use of a wide range of activities that contribute to and guarantee the possibility for people to participate in a variety of educational experiences in their lifespan;

- a flexibility and diversity of content, techniques and methods, but also of the time required for the completion of the programs, aiming at the creation of the most favorable conditions for the education of people of all ages, sexes and categories;

- the implementation of lifelong learning through formal, non-formal and atypical education;

- a gradual blending and exploitation of both educational parameters and social ones;

- democratization through the creation of opportunities for free participation of all;

- setting up a framework within which opportunities and incentives will be provided in order to expand and more effectively implement lifelong learning so as to ensure better education to citizens;

- cultivating and learning how people learn, self-assess and collaborate, with the ultimate goal to increase individual learning readiness and consequently overall progress;

- the recognition of the social role of education, which is the development of human potential to its fullest extent.

\subsection{Adult education}

Adult education spans the biggest part of a person's education, which begins with the completion of compulsory or initial education and continues through informal processes throughout their life (Kokkos, 2005). Adult education is the part of lifelong learning referring to adult learners (Mezirow, 2007). UNESCO formulated in 1976 a corresponding definition according to which "adult education is every educational process involving every content, level, and method, whether formal or not, or a process that extends over time or replaces initial education in schools, colleges and universities through which individuals who are considered adult within the society they are members of, develop their skills, enrich their knowledge, improve their technical and professional qualifications or turn them to other direction in order to bring about changes in their attitudes or behavior envisioning both full personal development and participation in a harmonized and robust social, economic and cultural growth" (Kokkos, 2005). 


\subsection{Participation requirements}

Adult learners decide to take part in a learning process so as to fulfill some specific needs, although it is obvious that in some cases their motivation does not stem from the existence of a particular need. There seems to be some kind of dual motivation where, on the one hand there is a "vague and not eloquently formulated sense of need" and on the other, the desire to learn something specific or to deal with a given problem (Rogers, 2002).

By "motivation" we mean "all those factors that affect patterns of behavior that are organized in a way related to a purpose". It is the inner force that drives a person to act in a certain way. With regard to motivation for learning, we might consider the driving force that activates the individual to learn, and keeps it focused on the educational process. These factors may be either external, distinguished by inducement or pressure forces, or internal - inherent, often stemming from the internalization of external factors and contributing as an internal impulse or desire to make a decision regarding a change in one's learning. In a classic research attempt in 1965, Johnstone and Rivera categorized the motivation of the participants in their research sample as follows (Leis, Tanner \& Arnett, 2009; Vergides, 2003):

- search for new employment,

- promotion in current working environment,

- further updating,

- recreational leisure,

- home-centered occupations,

- coping with daily routine,

- making new acquaintances,

- escape from the routine of everyday life,

- something else.

Table 1. Defining the reasons for participating in adult programs

(Data from the European-wide Eurostat research in 2007.

Percentages in total are given for the European Union and Greece.)

\begin{tabular}{|l|c|c|}
\hline Motivation reasons for participation in adult education programs & $\begin{array}{c}\text { Greece } \\
\%\end{array}$ & $\begin{array}{c}\text { E. U. } \\
\%\end{array}$ \\
\hline Acquiring knowledge and skills relating to an interesting subject & 76.7 & 32.0 \\
\hline Better performance of work tasks and/or better salary- earnings & 74.8 & 44.4 \\
\hline Acquiring knowledge and skills useful in everyday life & 52.4 & 25.5 \\
\hline Obligatory acquisition of a certificate & 48.6 & 10.1 \\
\hline Increasing the probability of finding a job or changing a profession & 25.5 & 11.6 \\
\hline Making acquaintances with young people or simply for entertainment & 20.6 & 8.8 \\
\hline Obligatory participation & 18.1 & 21.5 \\
\hline Reducing the risk of becoming unemployed & 16.0 & 12.3 \\
\hline Starting one's own business & 7.9 & 3.3 \\
\hline Other reasons & 4.3 & 6.2 \\
\hline
\end{tabular}

The Table 1 presents the findings of a pan-European research, conducted by Eurostat from 2007 to date, whose aim was to identify motivation for participation in adult education programs. In the first column the figures of the Greek sample are sorted in descending order and the pan-European average is to the right. The analysis of the data shows that in Greece over $75 \%$ associates their participation in adult education programs with searching for knowledge and skills relating to an interesting subject, but also with reasons relating to working issues like better performance of work tasks and advancement. At the same time, another $25.5 \%$ is found to have reported that they would be involved in training with a view to find a new job or change a profession, whereas $16 \%$ would do so, so as not to lose their current job, and about $8 \%$ would act accordingly so as to acquire the necessary qualifications in order to set up their own business. 
Approximately 50\% consider that it is important to acquire knowledge and skills for everyday life but also because it is compelling either in the sense of obtaining a certificate $(48.6 \%)$ or as a workplace requirement (18.1\%). Finally, 20.6\% would be involved in a program aspiring to new acquaintances, while another $4.3 \%$ would do so, for a number of other reasons.

\subsection{Participation restrictions}

Adults very often face difficulties that prevent their participation in educational programs as most of them have a lot of commitments and their living conditions and social roles are complex. These restrictive factors can be divided into three main categories, the first one including factors related to the organizing of the educational process, the second one including those dealing with the individuals' social commitments and duties, and the third category which involves internal obstacles related to the personality and psychology of those in question (Kokkos, 2005). In particular, in the first category there is a grouping of all those factors that refer to the organization of educational activity and include issues related to (Kokkos, 2005; Vergides, 2003; Roger, 2002; Courau, 2000):

- the place where the training takes place, and also the state of the property, but more importantly the distance the candidates would have to cover, especially when the use of a car or a means of mass transport is required;

- the cost of tuition fees, of educational materials or even that of the transportation of the trainees;

- the timing and, in particular, the total duration of the program and of the meetings, as well as the implementation period, the frequency and the scheduled time of the meetings;

- the facilities available that ensure comfortable living and effective attendance;

- materials and means, the absence of which may downgrade or even invalidate the benefits of education;

- the general conditions alluding to the state of the site (noise, heat, etc.) up to the number of participants and the quality of the trainers themselves;

- the selected teaching and assessment teaching methods, especially when these are familiar to the interested parties, though they may appear to be extremely demanding and "alien" to their educational habits and expectations;

- coordination, the absence of which may not only undermine the educational process but also cancel all educational objectives;

- the support provided during the educational process as well as when procedural matters occur, which will moderate the insecurity and anxiety of the participants and make their attendance more efficient;

- information on the existence of educational programs, on the curriculum and on all the necessary details, which will consequently increase interest and reduce stress and negative emotions which are caused due to the lack of knowledge regarding the characteristics of an educational program.

The second category includes restricting factors related to the commitments and duties of adults, which are relevant to their diverse roles, that are in particular summarized to the following (Kokkos, 2005; Malach, 2003; Vergides, 2003; Courau, 2000):

- adult occupational obligations, which under certain circumstances may cause fatigue, minimize leisure time and result in loss of mood; 
- the occupational status, since, because of its significance it may have an impact on lifelong learning, because if the adult is currently employed he/she may be involved with issues mentioned earlier but if the adult is unemployed issues of different nature may arise such as bad psychology, difficulty in programming etc.;

- the professional position occupied by an adult because it is likely to have a negative impact either physically or psychologically, taking up a lot of their time, keeping them away from their place of residence or even not allowing them to stay in a particular place for a long period of time. It has also been found that the type of profession significantly affects people's learning abilities as work improves the abilities of individuals in general. For example, professions that require intellectual work help individuals to strengthen their mental and learning faculties (Kapsalis, 2000; Tsiora \& Euclid, 1997);

- the marital status which affects mostly women in our country, Greece, mainly in single-parent families, as there are not always the necessary facilities available for childcare so that mothers would easily participate in an educational program;

- the financial condition of the people concerned, especially during the last period of the financial crisis, as this, on the one hand, prevents them from participating, especially when tuition fees are required, and on the other hand, disrupts the individual and suspends their participation;

- the support which an adult can have from their family background, work, and organized or non-governmental institutions;

- the roles that a person has taken over of their own free will or by law within the social framework which they often tend to increase their responsibilities leading, as a result, to the reduction of leisure time or even to non-participation, as in the case of military service;

- situations of social exclusion where people are on the fringe of society by being in penitentiary, nursing or other institutions or even totally shut out without having access to or being given the opportunity to participate in educational processes.

The third category refers to the internal obstacles a person encounters, mainly because of their personality, psychological state and physical condition,which more specifically comprises the following (Kokkos, 2005; Vergides, 2003; Dimitrakopoulos, 2005; Kleftaras, 2000; Courau, 2000):

- reasons related to demographic features such as gender, age, level of education, lack of prerequisites, etc.;

- reasons relating to their intellectual inefficiency;

- health reasons, as in the case of contagious diseases, mental illnesses, substance addiction, disabilities, etc.;

- prior knowledge, values and perceptions, to which adults adhere, invest emotionally, and consequently refrain from engaging in procedures that can challenge all these elements, because that indirectly would mean questioning their own personality;

- other personal reasons, which may be based on previously mentioned cases or on current circumstances;

- psychological factors, and in particular a combination of the unknown and the fear of failure, which is often reinforced by pre-existing negative school experiences, that threaten the prestige of adults, increase the pressure they feel on account of various obligations they are entangled with, and in the end, form a negative perspective regarding their participation in corresponding educational programs. 
On a quantitative level, analyzing the data from the Eurostat survey, with reference to the constraints the adults encounter as far as their participation in educational programs is concerned, we see that for $20.4 \%$ of the Greeks asked, the main deterrent is the lack of time due to family engagements. For $10.2 \%$, the constraints are due to the working environment and, in particular, due to overlapping programs. One third of the sample considers the economic factor to be more significant, while for $7.8 \%$ of the participants it is the absence of programs held at close range. Around five per cent (4.8\%) of the respondents report having no access to a computer or internet. Almost sixteen percent (15.9\%) think that the most important inhibiting factors are (a) health reasons with all the constraints that would follow on account of them, (b) the negative experiences they had when at school, and (c) the poor support they have from their family and work environment, as well as the inadequate organization (Eurostat, 2016).

Table 2. The reasons for blocking participation in adult programs

(Data from the pan-European Eurostat research in 2016.

Percentages are given for the European Union and Greece.)

\begin{tabular}{|l|c|c|}
\hline \multicolumn{1}{|c|}{$\begin{array}{c}\text { Reasons obstructing participation } \\
\text { in adult education programs }\end{array}$} & $\begin{array}{c}\text { Greece } \\
\%\end{array}$ & $\begin{array}{c}\text { E.U. } \\
\%\end{array}$ \\
\hline Lack of time due to family engagements & 20.4 & 7.6 \\
\hline Overlapping programs between education and work & 10.2 & 8.9 \\
\hline High cost & 7.3 & 6.0 \\
\hline Absence of programs held at close range & 2.2 & 1.2 \\
\hline Absence of suitable programs & 7.8 & 2.2 \\
\hline Health problems or difficulties related to age & 9.7 & 3.4 \\
\hline Negative experiences from school life & 5.3 & 6.3 \\
\hline Insufficient support and organization & 0.9 & 2.2 \\
\hline No access to a computer or internet & -9 & -2 \\
\hline Other personal reasons & -2 & 3.3 \\
\hline
\end{tabular}

2. Method

2.1 Empirical research to identify the reasons that motivate and obstruct adult participation in lifelong education programs

The survey is quantitative with a questionnaire and its main objective is to identify all those parameters that can influence the participation of adults in lifelong learning programs. The research tool was tested during the pilot application for its validity and reliability. In order to ensure the validity of the questionnaire, following the theoretical study of this question, a thorough selection process of the questions was conducted, to ensure that all aspects of the subject are covered and are easily understood, thanks to their accurate wording, by the respondents (Moustakas, 2017). For this reason closed-type questions were constructed using Likert-type scales, which ensure greater validity than open-ended questions (Cohen et al., 2000). In addition, a validity check of the content was carried out during the pilot research by experts both from the University of the Aegean and Adult Education institutions of the island.

More specifically, measurements about the apparent validity and validity of content were made by a group of experts, indicating that the questionnaire measures what it was originally intended for, with the use of appropriate questions (sum.> 4). As far as the reliability test is concerned, the Cronbach internal cohesion index [Alpha] was used. The Internal Cohesion Index constitutes a very significant reliability indicator of a research tool. It demonstrates the degree of homogeneity of questionnaire questions and assesses to what extent its questions form a reliable research tool (Moustakas, 2017). The reliability check of internal coherence was conducted to check the degree of homogeneity of questions and possibly to remove questions that disrupt the cohesion of the research tool and this process was repeated in the final sample values too. 
According to the Cronbach-A index of the main survey, the scale referring to the motivation reasons presents a ratio 0.786 and that of the blocking reasons is 0.761 , both of which indicate high levels of internal cohesion reliability (Roussos \& Tsaousis, 2011).

The research population was defined as the total population of the island of Rhodes ranging from 15 to 60 years of age, with about 78,000 inhabitants. The sample according to size and demographic data of the population was set at 1,500 of which about 1,100 completed questionnaires were finally collected (Andreadakis \& Vamvoukas, 2005). According to the population's stratification data, the questionnaire distribution strategy involved the whole island focusing mainly on the island's schools.

Exploratory research questions seek scientific answers on whether respondents' views on motivation and obstruction of their participation in adult education programs, vary according to age and gender.

With reference to the results of testing the relevance of motivation and obstruction reasons to gender and age, a regularity check for the values of the research variables was performed initially and then, the corresponding statistical criteria were used: (a) the parametric t-test criterion for independent samples, for gender, wherever the conditions were fulfilled, while for the rest the non-parametric Mann-Whitney and (b) the parametric One-way ANOVA for age, where the conditions were met, and the nonparametric Kruskal-Wallis for all the rest. In all cases the level of significance was 0.05 (Moustakas, 2018).

\subsection{Identity of the sample}

According to data from the statistical analysis, the sample of 1,088 residents of Rhodes Island consists of 522 men (48.0\%) and 566 women (52.0\%). With regard to age, 161 respondents (14.8\%) stated they were under 20, 249 (22.9\%) between 20-29, 327 (30.1\%) between 30-39, 241 (22.2\%) between 40-49, 87 (8.0\%) between 50-59 and 23 (2.1\%) over 59 years of age. Analyzing the figures relating to the educational level of the sample individuals it appears that $16 \%$ did not attend or did not complete their studies in high school, 47\% graduated successfully from this level and $37 \%$ pursued further studies either in an Institute of Vocational Training (IEK) or in tertiary education either on undergraduate or postgraduate level.

\subsection{Descriptive research results - Participation in Lifelong Learning Programs. Reasons for motivation and obstruction.}

This section presents the research data regarding the respondents' degree of concordance on specific proposals concerning their motivation for participation in lifelong learning programs (Nikolaides \& Dzubinski, 2016). According to the respondents' statements, the predominant reasons for their participation in such programs are referring to their personal pleasure related to their hobbies and interests (average degree of concordance 3.93), work-related reasons (average degree of concordance 3.86), social reasons (average degree of concordance 3.79), their tendency to share their concerns with others (average degree of concordance 3.75) and economic reasons (average degree of concordance 3.73).

The next set of questions, the research findings of which are presented, refer to the reasons that may actually limit or obstruct the participation of adults in education programs. Questions are divided into subgroups depending on the content of the inhibitory reasons they refer to, for which an index is calculated which expresses the degree of impact of the respective category:

- Educational/Organizational Reasons - 3.81

- Labor reasons - 3.56

- Economic reasons -3.27 
- Family reasons -3.23

- Personal reasons - 3.04

- Social reasons - 2.72

From the analysis of data it is found that respondents consider both the educational organizational indicator and that of the workplace to be really important, while on the contrary they attach less importance to the social one. The impact of personal reasons on the process of blocking participation is (average degree of concordance) 3.04.

Respondents consider that lack of preconditions and overlapping programs to be serious reasons (average degree of concordance 3.62), while the absence of means of transport, health grounds, age as well as their general attitude to lifelong learning have a minor impact on their participation in similar programs (average degree of concordance 2.52-3.07). In the second group where there is reference to family reasons the corresponding indicator is 3.23. From the analysis of the data of the corresponding questions it seems that lack of time due to family engagements (average grade 4.17) is of great importance. Less significant, as a constraint, is the lack of support from the family environment (average 3.21), as well as the refusal of the guardians (average 2.40). Third in line is the group, which is related to economic reasons, the impact of which appears moderate with a factor of 3.27. According to the statements of the participants in our research moderate significance is attributed to the reason for being unaffordable (average degree of concordance 3.46), to the lack of financial resources (average degree of concordance 3.63) and even less significance to the absence of means of transport(average degree of concordance 2.70). The next category refers to factors of a working nature, which may have a negative impact on the participation of adults in educational programs and has a factor of 3.56. According to the sample's statements, moderate importance is attributed to limited work-related utility (average degree of concordance 3.46) and to lack of support from the employer (average degree of concordance 3.66).

\subsection{Results of the survey based on inductive statistics}

The descriptive results of the survey have indicated clearly that the views of the respondents are diverse in many cases, and as a result it is very important to check to what extent there is a differentiation in their statements in relation to various demographic and other elements. Of course, it is then interesting to interpret and attempt to understand those elements in which significant differences are found to enrich the general debate on adult education. The values of the variables of interest are examined in relation to each and every other of the questions in the questionnaire in order to determine to what extent there are statistically significant differences. At this point, it should be noted that for reasons of economy only those cases where statistically significant differences have been identified are presented in this research paper. The results of the comparison of the survey data on gender and age are presented below.

\subsubsection{Result study according to gender}

The following table presents explicitly the extent to which respondents agree on each of the proposals, in order to further analyze their views on motivation, so as to attend adult education programs, for which statistically significant differences appear.

The results indicate that women consider labor (average 3.92 and 3.81) and economic (average 3.80 and 3.64) reasons more important than men as motivation factors $(\mathrm{t}(1072)=-2.290$, $\mathrm{p}=.022$ and $\mathrm{t}(1066)=-2.474, \mathrm{p}=.014$ respectively). Regarding more specific motivation reasons, women say they are motivated to a greater extent (average 3.80) than men (average 3.69) by "their tendency to share their concerns with others" $(\mathrm{t}(1073)=-1.966, \mathrm{p}=.050)$, and even for "personal pleasure related to their hobbies and interests" $(\mathrm{t}(1075)=-2.037, \mathrm{p}=.042)$. 
With reference to the varied statements coming from people of different gender, regarding the reasons for obstructing the attendance of adult education programs, in which statistically significant differences appear, it is found in all cases that women consider the following specific factors as more important than men. In particular, women (average 3.34) state that they consider their economic and family reasons to be more of an impediment than men do $(\mathrm{p}=.318)(\mathrm{t}(1083)=-3.173 \mathrm{p}=.002$ and $\mathrm{t}(1083)=-3.381, \mathrm{p}=.001$ respectively $)$. As far as the rest of the factors in these categories are concerned, they mark out the high cost of programs (average $3.54-3.37, \mathrm{t}(1079)=-2.544, \mathrm{p}=.011$ ), the lack of time due to family engagements (average 4.24$4.10, t(1082)=-2.701, \mathrm{p}=.007)$, the lack of support from the family environment (average 3.28$3.13, \mathrm{t}(1079)=-2.084, \mathrm{p}=.037)$ and the refusal of guardians for cases in which they can express an opinion (average 2.47-2.32, $\mathrm{t}(1059)=-1.997, \mathrm{p}=.046)$.

In terms of personal reasons, the most significant are health reasons, which women (average 3.16) consider to be more important than men (average 2.96) $(\mathrm{t}(1064)=-2.709 \mathrm{p}=.007)$ and the lack of means of transport(average $2.79-2.60, t(1059)=-2.648, p=.008)$. Finally, with regard to the reasons relating to the organizing body and the organization of the programs in general, they mark out the existence of overly long programs (average 3,47-3,30, $t(1056)=-2,835$, $\mathrm{p}=.005$ ), their programming at inconvenient hours (average $3.82-3.67, \mathrm{t}(1060)=-2.678, \mathrm{p}=.008$ ), the poor conditions (average 3.21-3.09, $\mathrm{t}(1050)=-2.001, \mathrm{p}=.046)$, the lack of programs held at close range, $(\mathrm{p} .3 .86-3.69, \mathrm{t}(1064)=-2.970, \mathrm{p}=.003)$ and the little information about their conducting (average 3.96-3.75, $\mathrm{t}(1064)=-3.260, \mathrm{p}=.001$ ).

\subsubsection{Result study according to age}

From the analysis of the question data, which shows a statistically significant difference, it is found that the younger participants appear to be motivated to a greater extent by their peers, up to the age of 29, and then less in inversely proportional way depending on the age increase $(\mathrm{f}(4 / 1072)=6.235$, average: $(<20) 3.15-(20-29) 2.79-(30-39) 2.77-(40-49) 2.69-$ (>49) $2.54, p=.000)$. A statistically significant difference is, also, found in the statement "to share their concerns with others", where the same model is presented with a gradual increase depending on age up to the age range of 40-49, and finally notably limited among older individuals $(\mathrm{H}(4 / 1070)=11.328$, average: $3.51-3.75-3.81-3.86-3.69, \mathrm{p}=.023)$. Also, with the statement "because it is a current trend" whose degree of motivation increases in inversely proportional way to the increase of age $(\mathrm{H}(4 / 1072)=10.846$, average: $2.46-2.23-2.1-2.1-1.99, \mathrm{p}=.028)$.

Regarding the differentiations in the degree of significance of the reasons for obstructing participation in relation to age, personal reasons are distinguished and, in particular, age limitations, where there is a reduction in the average as the age increases $(f(4 / 1048)=4.285$, average: $2.88-2.54-2.45-2.44-2.42, \mathrm{p}=.002)$ and also psychological reasons, such as anxiety, fear, low self-esteem etc., which they, too, do reduce as the age increases $(\mathrm{f}(4 / 1061)=2.067$, average: 2.84-2.75-2.59-2.59-2.50, $\mathrm{p}=.043$ ).

With regard to family - social reasons for blocking participation, the selection of the refusal of guardians and the general negative attitude of the social environment is limited as the age increases $(\mathrm{f}(4 / 1056)=2.436$, average: $2.57-2.45-2.38-2.36-2.12, \mathrm{p}=.046)$ and $(\mathrm{f}(4 / 1052)=$ 3.668, average: $2.59-2.42-2.34-2.30-2.12 \mathrm{p}=.006$ respectively).

The limited work-related utility of educational programs is a restrictive factor, especially among those younger than 20 (average 3.60) and between 20-29 years of age (average $3.55)$. It is then limited as the age increases but grows significantly among people aged 49 and over (average 3.54), $(\mathrm{f}(4 / 1072)=3.458, \mathrm{p}=.008)$.

Finally, with regard to the reasons related to the organizing party and the organization of the programs in general, "the lack of educational programs" is a factor which becomes more 
significant as the respondents' age increases $(\mathrm{f}(4 / 1063)=2.776$, average: $3 \cdot 94-4.01-4.13-4.17-4.23$, $\mathrm{p}=.026)$, "scheduling lessons in inconvenient days and hours", which seems to affect adults more as age increases ( $\mathrm{f}(4 / 1057)=6.658$, average: $3.60-3.62-3.77-3.79-3.93, p=.049)$ and "the lack of suitable educational structures" which affects participants in the study according to age $(f(4 / 1063)=2.465$, average: $3 \cdot 95-4.05-4 \cdot 15-4.16-4.19, p=.043)$.

\section{Discussion}

Following the analysis of research data, it is evident that citizens feel the lack of educational programs and are favorably disposed to lifelong learning. From the comparative research implementation of educational programs to different age groups, it seems that programs for young people could be made suitable for adults with the appropriate modifications.

From the analysis of the demographic data as it is conducted in this research, the independent "age" variable shows $46.5 \%$ differences in the variables related to lifelong learning, whereas the "gender" shows $36.5 \%$. In particular, from the analysis of the research data, 54 statistically significant differences related to age were identified as well as two dominant trends of differentiation, according to which the differences are increased or decreased depending on the age of the respondents.

In particular, referring to reasons for obstructing participation in educational processes of this nature, the absence of structures and programs is the one chosen to a larger extent by older people, whereas psychological reasons, refusal of guardians, various social parameters and age restrictions are the type of inhibiting reasons chosen by the younger respondents (Reis, 2008).

In the assessment section of the indicator for lifelong learning, although there is no differentiation in total, in individual statements men tend to believe strongly that continuous education reduces the risk of dismissal and at the same time upgrades the image of the employee. On the other hand, women believe strongly that continuous education is a more enjoyable engagement, a good example to follow for their children and something that increases their selfesteem, while they disagree more with the view that the employee should participate in a training program only after the employer's persistence in doing so (Jung \& Cervero, 2010; Reis, 2008; Boshier \& Collins, 2006).

The present research covered the region of the island of Rhodes. It highlighted the complexity of the factors that are conducive or inhibitory to the participation of individuals in educational programs in their lifespan. Taking into account the data provided through the statistical analysis it could be applied to the country as a whole, if conducted in different parts of diverse socioeconomic background, in order to assess the significance of adult participation in lifelong learning programs so as to enhance not only personal development but also progress and economic growth in general.

\section{Funding statement}

This research received no specific grant from any funding agency in the public, commercial or not-for-profit sectors.

\section{Conflict of interest statement}

The author declares that there is no conflict of interest. 


\section{References}

Andreadakis, N., \& Vamvoukas, M. (2005). Guide to the preparation and compilation of a written research paper. Athens: Atrapos.

Bergevin, P. (1995). The adult, his society and adult education: An overview. In: S. Merriam (Eds.), Selected writings on philosophy and adult education. Florida: Krieger Publishing Company.

Bigge, M. (1990). Learning theories. Athens: Patakis.

Boshier, R. (1980). Towards a learning society. Vancouver: Learning Press.

Courau, S. (2000). The basic "tools" of adult educator. Athens: Metaihmio.

Dimitrakopoulos, G. (2005). Who's afraid of “Local Agenda 21"? In: A. Georgopoulos (Ed.), Environmental Education. The new civilization that emerges. Athens: Gutenberg.

Edwards, R. (2003). Lifelong learning: A recurrent education? In: J. Field \& M. Leicester (Eds.), Lifelong Learning. Education across the lifespan. New York: Routledge Falmer.

Goad, L. (1984). Preparing teachers for lifelong education. Hamburg: UNESCO Institute for Education and Pergamon Press.

Jung, J., \& Cervero, R. (2010). The social, economic and political context of adult participation in undergraduate programs: a state-level analysis. International Journal of Lifelong Education, 21(4), 305-320.

Kapsalis, A. (2006). Educational psychology. Athens: Kyriakidi Bros SA.

Kleftaras, C. (2000). Cognitive specificity of depression and anxiety: Methodological issues and research data. Psychology, 7(1), 46-62.

Kokkos, A. (2005). Adult Education. Detecting the field. Athens: Metaihmio.

Koronaiou, A. (2002). Educating outside school. The contribution of audiovisual media and new technologies. Athens: Metaihmio.

Leis, J., Tanner, J., \& Arnett, J. (2009). Learning and development during the first stage of adulthood. In: M. Smith \& N. DeFrates-Densch (Eds.), Handbook of research on adult learning and development. New York: Routledge.

Malach, A. (2003). Black and other ethnic minority communities learning needs. In: J. Field \& M. Leicester (Eds.), Lifelong Learning. Education across the lifespan. New York: Routledge Falmer.

Mezirow, J. (2007). Learning to think like an adult. Basic concepts of transformation theory. In: J. Mezirow et al. (Eds.), Transforming learning. Athens: Metaihmio.

Vergidis, D. (2003). Designing adult education programs for vulnerable social groups. In: D. Vergides (Ed.), Adult Education. Contributing to the specialization of executives and trainers. Athens: Greek Letters. 
L. Moustakas - Motivation and Obstacles to Adult Participation in Lifelong Learning...

C O A $\mathbf{s}$ 